\title{
If It Works, Don't Touch It? A Cell-Based Approach to Studying 2-[18F]FDG Metabolism
}

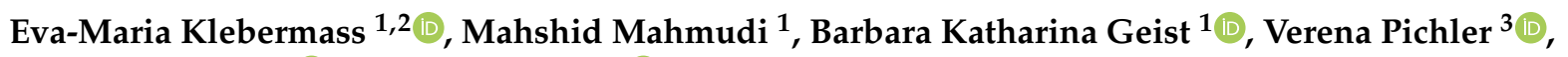 \\ Chrysoula Vraka ${ }^{1} \mathbb{D}$, Theresa Balber ${ }^{1,4}{ }^{\mathbb{D}}$, Anne Miller ${ }^{5}$, Arvand Haschemi ${ }^{5}$, Helmut Viernstein ${ }^{2}$,
} Nataliya Rohr-Udilova ${ }^{6}{ }^{(}$, Marcus Hacker ${ }^{1} \mathbb{D}$ and Markus Mitterhauser ${ }^{1,4, *}$

1 Division of Nuclear Medicine, Department of Biomedical Imaging and Image-Guided Therapy,

Medical University of Vienna, 1090 Vienna, Austria; eva-maria.klebermass@meduniwien.ac.at (E.-M.K.); mahshid.mahmudi@fhwn.ac.at (M.M.); barbara.geist@meduniwien.ac.at (B.K.G.); chrysoula.vraka@meduniwien.ac.at (C.V.); theresa.balber@lbiad.lbg.ac.at (T.B.); marcus.hacker@meduniwien.ac.at (M.H.)

2 Division of Pharmaceutical Technology and Biopharmaceutics, Department of Pharmaceutical Sciences, University of Vienna, 1090 Vienna, Austria; helmut.viernstein@univie.ac.at

3 Division of Pharmaceutical Chemistry, Department of Pharmaceutical Sciences, University of Vienna, 1090 Vienna, Austria; verena.pichler@univie.ac.at

4 Ludwig Boltzmann Institute Applied Diagnostics, 1090 Vienna, Austria

5 Department of Laboratory Medicine, Medical University of Vienna, 1090 Vienna, Austria; annelisabethmiller@googlemail.com (A.M.); arvand.haschemi@meduniwien.ac.at (A.H.)

check for updates

Citation: Klebermass, E.-M.; Mahmudi, M.; Geist, B.K.; Pichler, V.; Vraka, C.; Balber, T.; Miller, A.; Haschemi, A.; Viernstein, H.; Rohr-Udilova, N.; et al. If It Works, Don't Touch It? A Cell-Based Approach to Studying 2-[ $\left.{ }^{18} \mathrm{~F}\right] \mathrm{FDG}$ Metabolism. Pharmaceuticals 2021, 14, 910. https://doi.org/10.3390/ ph14090910

Academic Editor: Martina Benešová

Received: 30 July 2021

Accepted: 6 September 2021

Published: 9 September 2021

Publisher's Note: MDPI stays neutral with regard to jurisdictional claims in published maps and institutional affiliations.

Copyright: (c) 2021 by the authors. Licensee MDPI, Basel, Switzerland. This article is an open access article distributed under the terms and conditions of the Creative Commons Attribution (CC BY) license (https:// creativecommons.org/licenses/by/ $4.0 /)$.
6 Division of Gastroenterology and Hepatology, Department of Internal Medicine III, Medical University of Vienna, 1090 Vienna, Austria; nataliya.rohr-udilova@meduniwien.ac.at

* Correspondence: markus.mitterhauser@meduniwien.ac.at

\begin{abstract}
The glucose derivative 2- $\left[{ }^{18} \mathrm{~F}\right]$ fluoro-2-deoxy-D-glucose $\left(2-\left[{ }^{18} \mathrm{~F}\right] \mathrm{FDG}\right)$ is still the most used radiotracer for positron emission tomography, as it visualizes glucose utilization and energy demand. In general, $2-\left[{ }^{18} \mathrm{~F}\right] \mathrm{FDG}$ is said to be trapped intracellularly as 2- $\left[{ }^{18} \mathrm{~F}\right] \mathrm{FDG}-6$-phosphate, which cannot be further metabolized. However, increasingly, this dogma is being questioned because of publications showing metabolism beyond 2- $\left[{ }^{18}\right.$ F]FDG-6-phosphate and even postulating 2-[ $\left.{ }^{18} \mathrm{~F}\right]$ FDG imaging to depend on the enzyme hexose-6-phosphate dehydrogenase in the endoplasmic reticulum. Therefore, we aimed to study 2- $\left[{ }^{18}\right.$ F]FDG metabolism in the human cancer cell lines HT1080, HT29 and Huh7 applying HPLC. We then compared 2- $\left[{ }^{18} \mathrm{~F}\right] \mathrm{FDG}$ metabolism with intracellular tracer accumulation, efflux and the cells' metabolic state and used a graphical Gaussian model to visualize metabolic patterns. The extent of $2-\left[{ }^{18} \mathrm{~F}\right] \mathrm{FDG}$ metabolism varied considerably, dependent on the cell line, and was significantly enhanced by glucose withdrawal. However, the metabolic pattern was quite conserved. The most important radiometabolites beyond 2- $\left[{ }^{18} \mathrm{~F}\right] \mathrm{FDG}-6-$ phosphate were 2-[ $\left[{ }^{18} \mathrm{~F}\right]$ FDMannose-6-phosphate, 2- $\left[{ }^{18} \mathrm{~F}\right] \mathrm{FDG}-1,6$-bisphosphate and 2- $\left[{ }^{18} \mathrm{~F}\right] \mathrm{FD}-$ phosphogluconolactone. Enhanced radiometabolite formation under glucose reduction was accompanied by reduced efflux and mirrored the cells' metabolic switch as assessed via extracellular lactate levels. We conclude that there can be considerable metabolism beyond 2-[ $\left.{ }^{18} \mathrm{~F}\right] \mathrm{FDG}-6$-phosphate in cancer cell lines and a comprehensive understanding of $2-\left[{ }^{18} \mathrm{~F}\right] \mathrm{FDG}$ metabolism might help to improve cancer research and tumor diagnosis.
\end{abstract}

Keywords: 2-[ $\left.{ }^{18} \mathrm{~F}\right] \mathrm{FDG}$; 2- $\left[{ }^{18} \mathrm{~F}\right] \mathrm{FDG}$ metabolism; PET-tracer metabolism; molecular imaging; cancer metabolism

\section{Introduction}

The radioactively labelled glucose derivative $2-\left[{ }^{18} \mathrm{~F}\right]$ fluoro-2-deoxy-D-glucose $\left(2-\left[{ }^{18} \mathrm{~F}\right] \mathrm{FDG}\right)$ is still the most used tracer in positron emission tomography (PET) [1,2]. In principle, this tracer is said to visualize the so-called Warburg Effect, which is described as a shift towards glycolysis and lactate overproduction despite a normoxic environment $[2,3]$. 
This ineffective way to generate energy causes cells to consume more glucose [3]. As this is a major feature of most tumors, PET imaging with $2-\left[{ }^{18} \mathrm{~F}\right] \mathrm{FDG}$, together with computer tomography (CT), is an indispensable tool for the precise localization and simultaneous metabolic characterization of malignant lesions. Aside from cancer diagnosis or staging, $2-\left[{ }^{18} \mathrm{~F}\right] \mathrm{FDG}$ is used for the assessment of myocardial viability and the characterization and imaging of neurodegenerative diseases [1,2]. Firstly, higher glucose utilization might also occur naturally in healthy tissues such as brain (potentially complicating diagnosis), or at sites of inflammation (causing false-positive results in cancer diagnosis) [1,2]. Moreover, because of their metabolic makeup, some cancers by nature show low 2- $\left[{ }^{18}\right.$ F]FDG avidity [4], calling for more specific, receptor-based tracers.

Although 2-[ $\left.{ }^{18} \mathrm{~F}\right] \mathrm{FDG}$ has been widely used and comprehensively studied, its exact mode of action remains unclear. In a study by $\mathrm{Li}$ et al. with mice bearing peritoneal carcinomatosis and subcutaneous tumors, $2-\left[{ }^{18} \mathrm{~F}\right] \mathrm{FDG}$ uptake was presented as a readout for hypoxia (anaerobic glycolysis) rather than depicting the Warburg Effect (aerobic glycolysis) [5]. In other studies with non-small cell lung cancer patients [6,7], where 2-[18 F]FDG PET was combined with [13C]glucose tracing, enhanced 2- $\left[{ }^{18} \mathrm{~F}\right] \mathrm{FDG}$ uptake did not correlate to glycolytic metabolism, but to respiration [6] and to the proliferation index [7]. The latter study hence suggests $2-\left[{ }^{18} \mathrm{~F}\right] \mathrm{FDG}$ PET-signal to be a readout for the use of glucose in pathways other than glycolysis.

Moreover, 2- $\left[{ }^{18} \mathrm{~F}\right] \mathrm{FDG}$ 's own intracellular "standstill" after phosphorylation is being questioned. In general, 2- $\left[{ }^{18} \mathrm{~F}\right] \mathrm{FDG}$ is taken up via glucose transporters, but unlike glucose it is said to be trapped as $2-\left[{ }^{18} \mathrm{~F}\right]$ FDG-6-phosphate $\left(2-\left[{ }^{18} \mathrm{~F}\right] \mathrm{FDG}-6-\mathrm{P}\right)$ after its phosphorylation by hexokinase ("metabolic trapping"). In contrast to glucose-6-phosphate, the isomerization to an analogue of fructose-6-phosphate, which would be necessary for further processing through the glycolytic pathway, is hindered by the fluoride in position 2 [1,2]. Moreover, 2-[ $\left.{ }^{18} \mathrm{~F}\right]$ FDG PET-signal quantification nowadays still builds on the assumption that $2-\left[{ }^{18} \mathrm{~F}\right] \mathrm{FDG}-6-\mathrm{P}$ is the only metabolite. The refined Sokoloff compartment model used for quantification lists three or four rate constants, describing the transport of 2-[18 F]FDG from blood pool to tissue, the redistribution of $2-\left[{ }^{18} \mathrm{~F}\right] \mathrm{FDG}$ into blood, phosphorylation leading to intracellular retention and occasionally the dephosphorylation of $2-\left[{ }^{18} \mathrm{~F}\right] \mathrm{FDG}-6-\mathrm{P}$ by glucose-6-phosphatase (G6Pase) [8], as seen in liver tissue due to gluconeogenesis [9]. However, although $2-\left[{ }^{18} \mathrm{~F}\right] \mathrm{FDG}$ cannot be processed through glycolysis, it can still be metabolized beyond 2-[ ${ }^{18}$ F]FDG-6-P [10]. Notably, the glucose analogue seems to be shuttled into glycogen metabolism or the pentose phosphate pathway (PPP) [11]. Its metabolites have mostly been analyzed using its non-radioactive analogue 2-deoxy-2-fluoro-D-glucose and 19F-NMR [11-13]. However, this approach demands the application of vast amounts of nonradioactive FDG, which could - due to mass effects-result in a different outcome when compared to trace amounts used with $2-\left[{ }^{18} \mathrm{~F}\right] \mathrm{FDG}$. Other groups that tested metabolism of the radioactive form $2-\left[{ }^{18} \mathrm{~F}\right] \mathrm{FDG}$ in xenograft mice and rats detected fewer metabolites, potentially due to sensitivity limitations of their HPLC system [14,15].

Recently, research on $2-\left[{ }^{18} \mathrm{~F}\right] \mathrm{FDG}$ metabolism has gained new momentum with publications describing intracellular 2-[ $\left.{ }^{18} \mathrm{~F}\right] \mathrm{FDG}$ accumulation as specifically being a function of hexose-6-phosphate dehydrogenase (H6PD), the first enzyme of the oxidative branch of the PPP located in the endoplasmic reticulum (ER) $[16,17]$.

Although 2-[18 F]FDG is increasingly replaced by more specific PET-tracers, it is still an indispensable tool in nuclear medicine. While the simplistic model of the tracer's intracellular trapping might be sufficient for some clinical questions, an in-depth understanding of its intracellular fate could improve basic cancer research or cancer diagnosis. We hypothesized that 2- $\left[{ }^{18} \mathrm{~F}\right] \mathrm{FDG}$ metabolism would differ significantly in cancer cell lines of different tumor entities, as well as under different glucose conditions. Therefore we studied the 2- $\left[{ }^{18} \mathrm{~F}\right] \mathrm{FDG}$ metabolism in human cell lines of fibrosarcoma (HT1080), colorectal adenocarcinoma (HT29) and hepatocellular carcinoma (Huh7). We aimed to elucidate metabolic patterns and pathways involved in the tracer's metabolism to create a basis for a better understanding of cancer-relevant $2-\left[{ }^{18} \mathrm{~F}\right] \mathrm{FDG}$ accumulation and efflux. 


\section{Results}

\subsection{Enzymatic In Vitro Preparation and Verification of Radiometabolites}

To properly identify the radiometabolites of $2-\left[{ }^{18} \mathrm{~F}\right] \mathrm{FDG}$, we started to synthesize potential radiometabolites via enzymatic in vitro preparation. After adapting the HPLC assay by Rokka et al. [18] to our system in terms of gradient profile and run time (Table S1), we could verify the identity of the following radiometabolites: $2-\left[{ }^{18} \mathrm{~F}\right]$ FDG1-phosphate $\left(2-\left[{ }^{18} \mathrm{~F}\right]\right.$ FDG-1-P, retention time (RT) 7 $\left.\mathrm{min}\right), 2-\left[{ }^{18} \mathrm{~F}\right] \mathrm{FDG}-6-\mathrm{P}$ (RT 9.5 $\left.\mathrm{min}\right)$, 2-[ ${ }^{18}$ F]FDMannose-6-phosphate $\left(2-\left[{ }^{18} \mathrm{~F}\right]\right.$ FDM-6-P, RT 12 min), uridine diphosphate-2$\left[{ }^{18} \mathrm{~F}\right]$ FDG (UDP-2- $\left[{ }^{18} \mathrm{~F}\right]$ FDG, RT 21 min), 2- $\left[{ }^{18} \mathrm{~F}\right] \mathrm{FD}$-phosphogluconolactone $\left(2-\left[{ }^{18} \mathrm{~F}\right] \mathrm{FD}-\right.$ PGL, RT 25 $\mathrm{min})$ and 2-[ $\left.{ }^{18} \mathrm{~F}\right] \mathrm{FDG}-1,6-$ bisphosphate (2-[ $\left.\left[{ }^{18} \mathrm{~F}\right] \mathrm{FDG}-1,6-\mathrm{P}_{2}, \mathrm{RT} \sim 28 \mathrm{~min}\right)$. Figure $1 \mathrm{~A}$ shows representative chromatograms of the reference radiometabolites and corresponding chemical structures, while Figure 1B shows the workflow of the enzymatic in vitro synthesis of reference radiometabolites.

\section{Enzymatic in vitro synthesis of reference radiometabolites}
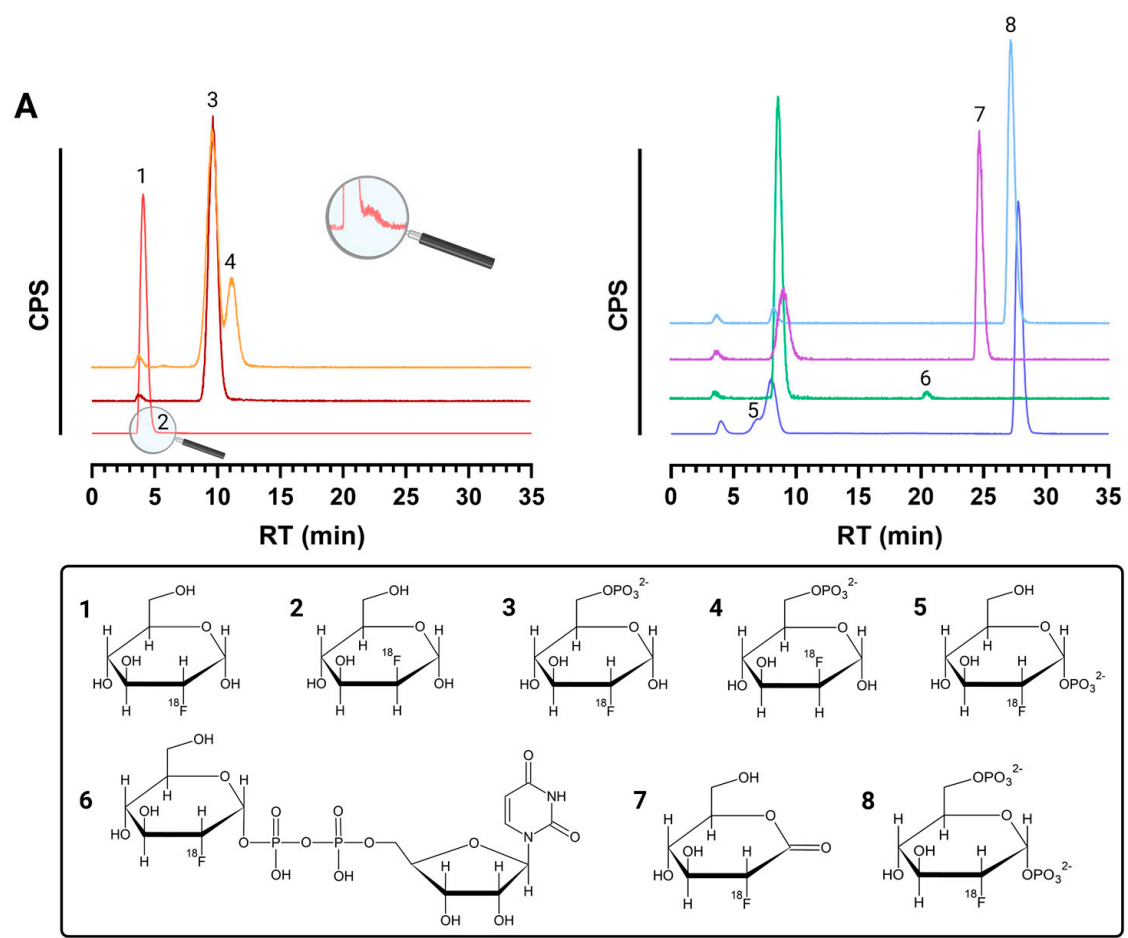

B

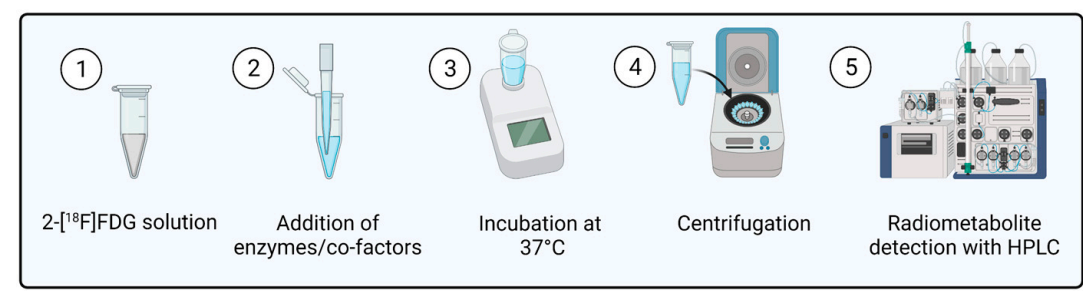

Figure 1. (A) shows representative chromatograms of the reference radiometabolites that were prepared via enzymatic in vitro synthesis and corresponding chemical structures. Each color represents the chromatogram of a different reference compound. $1=2-\left[{ }^{8} \mathrm{~F}\right] \mathrm{FDG}, 2=2-\left[{ }^{18} \mathrm{~F}\right] \mathrm{FDM}$, $3=2-\left[{ }^{18} \mathrm{~F}\right]$ FDG-6-P, $4=2-\left[{ }^{18} \mathrm{~F}\right]$ FDM-6-P, $5=2-\left[{ }^{18} \mathrm{~F}\right]$ FDG-1-P, 6 = UDP-2- $\left[{ }^{18} \mathrm{~F}\right]$ FDG, $7=2-\left[{ }^{18} \mathrm{~F}\right]$ FD-PGL, $8=2-\left[{ }^{18} \mathrm{~F}\right] \mathrm{FDG}-1,6-\mathrm{P}_{2}$. (B) shows the corresponding workflow of enzymatic in vitro synthesis of reference radiometabolites. Created with BioRender.com (accessed on 4 September 2021) based on HPLC raw data and graphs from Prism 7.03 software. 
We could not identify the radiometabolites at $\sim 19.5, \sim 22, \sim 23.5, \sim 27$ and $\sim 29.5 \mathrm{~min}$. However, the radiometabolites at $\sim 22, \sim 23.5$ and $\sim 27$ min never exceeded $0.1,0.3$ and $0.05 \%$, respectively. 2-[ $\left.{ }^{18} \mathrm{~F}\right]$ FDG-6-P and 2-[ $\left.{ }^{18} \mathrm{~F}\right] \mathrm{FDM}-6-\mathrm{P}$ were not fully separable despite HPLC optimization. Rokka et al. [18] reported that UDP-2-[ $\left.{ }^{18} \mathrm{~F}\right] \mathrm{FDG}$ was not synthesized because when adding phosphoglucomutase (PGM), the conversion of 2-[ $\left.{ }^{18} \mathrm{~F}\right]$ FDG-6-P to 2- $\left[{ }^{18} \mathrm{~F}\right] \mathrm{FDG}-$ 1,6- $\mathrm{P}_{2}$ via 2-[ $\left.{ }^{18} \mathrm{~F}\right]$ FDG-1-P is always favored over UDP-2- $\left[{ }^{18} \mathrm{~F}\right] \mathrm{FDG}$ formation in the presence of hexokinase. Therefore, we filtered our 2-[ $\left.{ }^{18} \mathrm{~F}\right] \mathrm{FDG}-6-\mathrm{P}$ solution containing hexokinase through a $30 \mathrm{kDa}$ filter prior to the addition of PGM, uridine triphosphate (UTP) and UDPglucose-pyrophosphorylase (UGPase). However, when we additionally added glucose-1,6bisphosphate, ethylenediaminetetraacetic acid (EDTA) and bovine serum albumin (BSA) to the solution after filtering, with or without UTP and UGPase, $2-\left[{ }^{18} \mathrm{~F}\right]$ FDG-1,6-P 2 was always the main metabolite after $\sim 2.5 \mathrm{~h}$. UDP-2-[ $\left.{ }^{18} \mathrm{~F}\right] \mathrm{FDG}$ was not produced. Interestingly, when we did not introduce any additional compounds to the filtrate mixed with UTP and UGPase, 2-[ $\left.{ }^{18} \mathrm{~F}\right] \mathrm{FDG}-1,6-\mathrm{P}_{2}$ was not or was only merely produced and we finally saw a metabolite at $\sim 21 \mathrm{~min}$, namely UDP-2-[ $\left.{ }^{18} \mathrm{~F}\right] \mathrm{FDG}$ (Figure 1A). We observed that 2- $\left[{ }^{18} \mathrm{~F}\right] \mathrm{FDG}-$ $1,6-\mathrm{P}_{2}$, a natural intermediate of the conversion of $2-\left[{ }^{18} \mathrm{~F}\right]$ FDG-6-P to $2-\left[{ }^{18} \mathrm{~F}\right] \mathrm{FDG}-1-\mathrm{P}$, is also produced in the absence of hexokinase. Adding glucose-1,6-bisphosphate, EDTA and BSA seemed to shift the equilibrium towards the intermediate 2-[ $\left.{ }^{18} \mathrm{~F}\right] \mathrm{FDG}-1,6-\mathrm{P}_{2}$ and UDP-2-[18 F]FDG cannot be built. We once also detected an additional peak at $\sim 7 \mathrm{~min}$ after around $2 \mathrm{~h}$ when synthesizing $2-\left[{ }^{18} \mathrm{~F}\right] \mathrm{FDG}-1,6-\mathrm{P}_{2}$, which should be $2-\left[{ }^{18} \mathrm{~F}\right] \mathrm{FDG}-1-\mathrm{P}$ (Figure 1A).

Furthermore, we identified the peak at $12 \mathrm{~min}$ as 2-[ $\left[{ }^{18} \mathrm{~F}\right] \mathrm{FDM}-6-\mathrm{P}$ (Figure 1A). The injection of pure 2-[ $\left.{ }^{18} \mathrm{~F}\right]$ FDG showed an additional peak with an RT of $\sim 6 \mathrm{~min}$. This peak

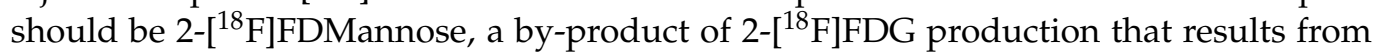
epimerization during alkaline hydrolysis (Figure 1A) [19]. Furthermore, we synthesized 2$\left[{ }^{18}\right.$ F]FD-PGL using two different commercially available, recombinant glucose-6-phosphate dehydrogenases (G6PDs) (Figure 1A). As 2-[ ${ }^{18}$ F]FD-PGL is not stable [20], the peak at $\sim 25 \mathrm{~min}$ can also be the decomposition product $2-\left[{ }^{18} \mathrm{~F}\right] \mathrm{FD}$-phosphogluconate or a mixture of both.

Overall, we verified the identity of three more radiometabolites (2- $\left[{ }^{18} \mathrm{~F}\right] \mathrm{FDG}-1-\mathrm{P}, 2-$ $\left[{ }^{18} \mathrm{~F}\right]$ FDM-6-P and UDP-2-[ $\left.{ }^{18} \mathrm{~F}\right]$ FDG) with enzymatic in vitro synthesis as compared to Rokka et al. [18], facilitating future analyses of 2-[ $\left.{ }^{18} \mathrm{~F}\right] \mathrm{FDG}$ metabolism.

2.2. Intracellular Accumulation and Metabolism of 2-[ ${ }^{18}$ F]FDG in HT1080 (Fibrosarcoma), HT29 (Colorectal Adenocarcinoma) and Huh7 (Hepatocellular Carcinoma)

$2-\left[{ }^{18} \mathrm{~F}\right]$ FDG was applied to the cells either under glucose $(1.13 \mathrm{~g} / \mathrm{L})$, glucose-reduced $(0.13 \mathrm{~g} / \mathrm{L})$ or starving conditions (glucose-reduced medium 1 or $2 \mathrm{~h}$ prior to $2-\left[{ }^{18} \mathrm{~F}\right] \mathrm{FDG}$ addition). Figure 2 summarizes the workflow of experiments determining $2-\left[{ }^{18} \mathrm{~F}\right]$ FDG accumulation and 2-[ $\left.{ }^{18} \mathrm{~F}\right]$ FDG metabolism in cancer cells. Under glucose conditions, the highest 2- $\left[{ }^{18} \mathrm{~F}\right]$ FDG accumulation in \% applied dose (\% AD) per $10^{4}$ cells after $1 \mathrm{~h}$ was seen in Huh7 (0.57 $\pm 0.04 \%)$, followed by HT1080 (0.22 $\pm 0.01 \%)$ and HT29 (0.13 $\pm 0.02 \%)$ (Figure 3A). Contrary to this, under glucose-reduced conditions, HT29 and Huh7 showed similar accumulation (18 $\pm 4 \%$ and $14 \pm 2 \%$ ), while there was significantly higher 2$\left[{ }^{18} \mathrm{~F}\right]$ FDG accumulation per $10^{4}$ cells in HT1080 (34 $\pm 4 \%$ ) (Figure 3A).

Analysis of lactate concentration in supernatants after the experiments showed that extracellular lactate was more than twice as high for HT29 and HT1080 under glucose conditions (HT29: $3.7 \pm 0.5 \% \mathrm{ng} / \mu \mathrm{L}$; HT1080: $3.6 \pm 0.5 \% \mathrm{ng} / \mu \mathrm{L}$ ) compared to glucosereduced conditions (HT29: $1.7 \pm 0.3 \% \mathrm{ng} / \mu \mathrm{L}$; HT1080: $1.6 \pm 0.1 \% \mathrm{ng} / \mu \mathrm{L}$ ). In Huh7, the difference between glucose and glucose-reduced conditions was slightly smaller with $3.5 \pm 0.3 \%$ vs. $2.0 \pm 0.2 \% \mathrm{ng} / \mu \mathrm{L}$ (Figure $3 \mathrm{~B}$ ). These data indicate a metabolic switch in all three cell lines following glucose reduction. 


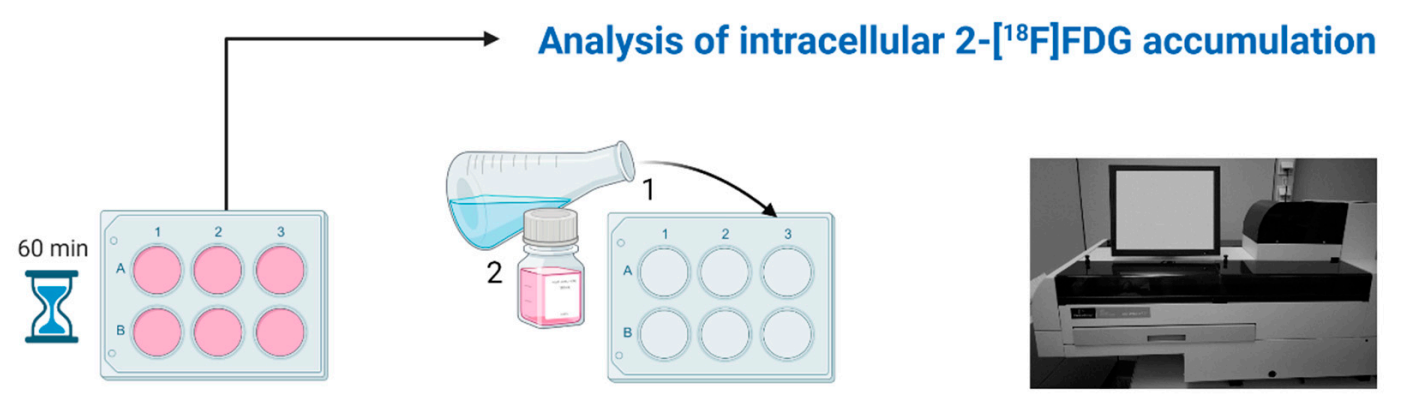

(1) $2-\left[{ }^{18} \mathrm{~F}\right] \mathrm{FDG}$ accumulation 3 human cancer cell lines, $1 \mathrm{MBq} / \mathrm{mL}$ in MEM or glucose-reduced DMEM
(2) Washing and cell detachment Cells washed twice with PBS, detached with Accutase, and resuspended
(3) Gamma counter measurement $100 \mu \mathrm{L}$ aliquots of cell suspension, blanks and references

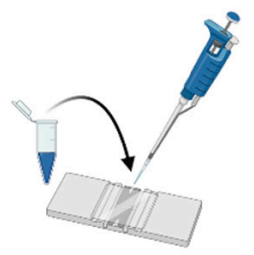

(4) Cell counting

Same aliquot mixed with trypan blue, Neubauer chamber

\section{Analysis of $2-\left[{ }^{18} \mathrm{~F}\right] \mathrm{FDG}$ metabolism}

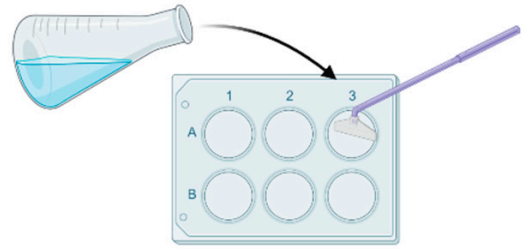

(2) Cell lysis

Cells washed twice with PBS, scratched off and lysed with $\mathrm{MeOH}$

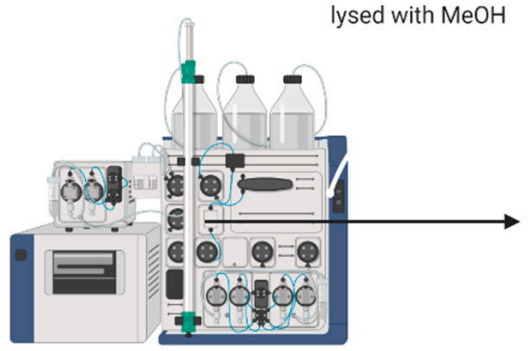

4) Analysis with HPLC

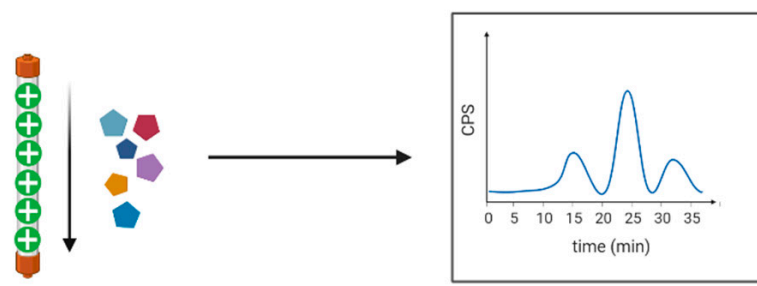

Separation of metabolites with an anion exchanger column

Analysis of radiometabolites with a radiodetector

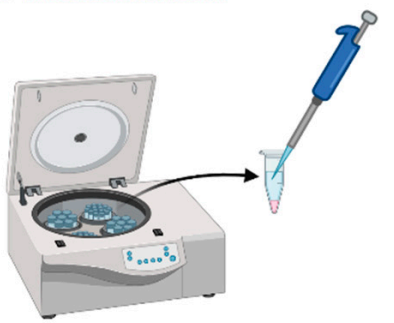

(3) Centrifugation

$4 \mathrm{~min} / 4^{\circ} \mathrm{C} / 13684 \mathrm{~g}$, and collection of supernatant

Figure 2. Workflow of experiments determining intracellular 2- $\left[{ }^{18}\right.$ F $]$ FDG accumulation and metabolism. Adapted from "Protein Purification by Size-Exclusion Chromatography" by BioRender.com (accessed on 4 September 2021). Retrieved from https:/ / app.biorender.com/biorender-templates. 
A

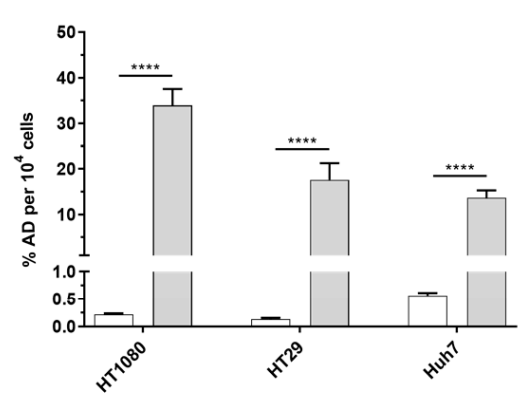

C

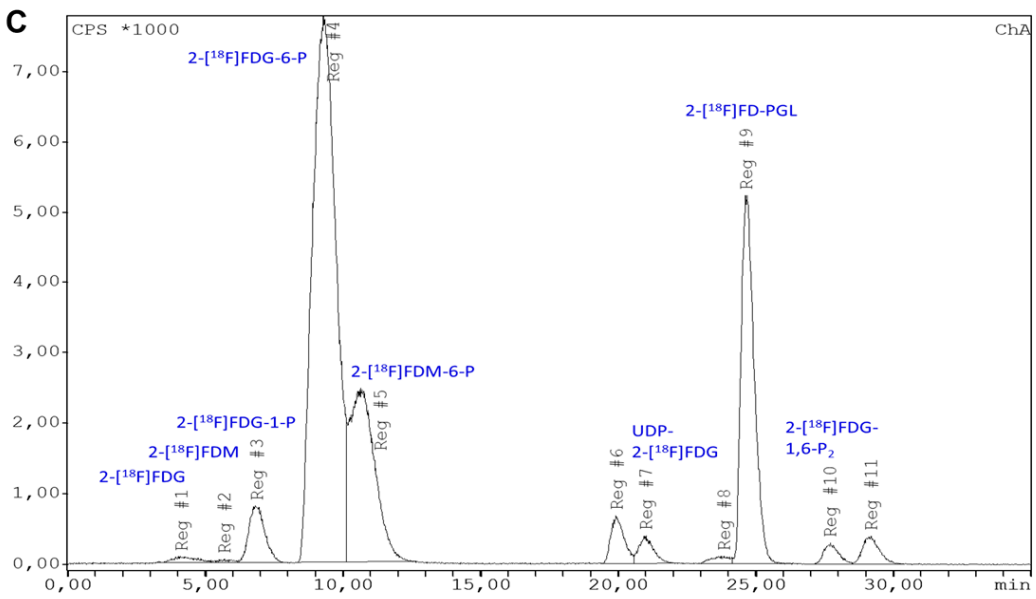

B Lactate concentration in supernatants

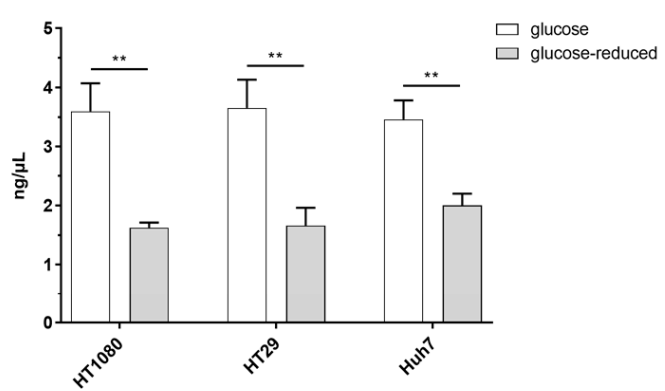

D Radiometabolites different from 2-[ $\left.{ }^{18} \mathrm{~F}\right] \mathrm{FDG}-6-\mathrm{P}$

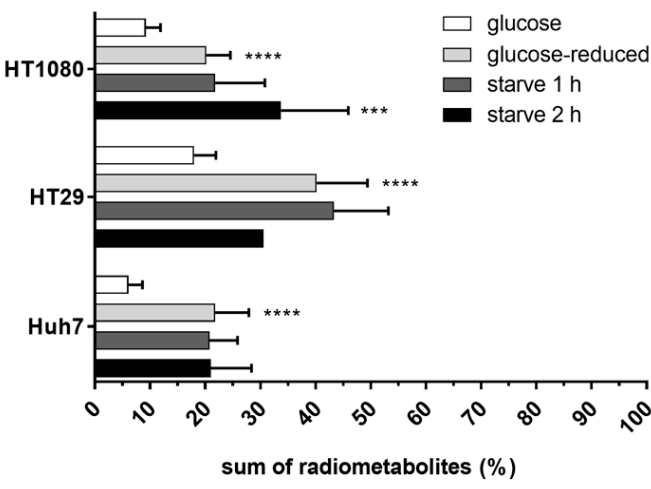

Figure 3. Total intracellular 2-[ $\left.{ }^{18} \mathrm{~F}\right] \mathrm{FDG}$ accumulation after $1 \mathrm{~h}(\mathrm{~A})$ and lactate concentration in the supernatants at the end of the experiment $\left(^{* *} p \leq 0.01\right)(B)$. (C) shows a representative image of the radiometabolite pattern under glucosereduced conditions in HT29 after $1 \mathrm{~h}$ and (D) the sum of radiometabolites other than $2-\left[{ }^{18} \mathrm{~F}\right] \mathrm{FDG}-6-\mathrm{P}$ after $1 \mathrm{~h}$ in $\%$ ${ }^{* * * *} p \leq 0.0001,{ }^{* * *} p \leq 0.001$ compared to glucose conditions). Conditions: glucose $=1.13 \mathrm{~g} / \mathrm{L}$, glucose-reduced $=0.13 \mathrm{~g} / \mathrm{L}$, starve $=$ glucose-reduced medium 1 or $2 \mathrm{~h}$ prior to $2-\left[{ }^{18} \mathrm{~F}\right] \mathrm{FDG}$ addition. If not visible, the error bars are within the margin of the symbols.

Overall, we could detect up to 12 radiometabolites in HPLC when stopping 2- $\left[{ }^{18} \mathrm{~F}\right] \mathrm{FDG}$ accumulation after $1 \mathrm{~h}$. Figure $3 \mathrm{C}$ shows a representative image of the metabolic pattern in HT29 using glucose-reduced medium, Figure 3D summarizes the extent of metabolism beyond 2- $\left[{ }^{18} \mathrm{~F}\right]$ FDG and 2- $\left[{ }^{18} \mathrm{~F}\right]$ FDG-6-P in the three cell lines. Except for the metabolite at $\sim 27$ min, which was only observed in HT1080, all radiometabolites were detected in all three cell lines. Under glucose conditions, HT29 showed the highest levels of radiometabolites other than 2-[ $\left.{ }^{18} \mathrm{~F}\right]$ FDG-6-P after $1 \mathrm{~h}$ with $18 \pm 4 \%$, followed by HT1080 $(9 \pm 3 \%)$ and Huh7 $(6 \pm 3 \%)$. It was the same cell line that showed the highest radiometabolite formation under glucose-reduced conditions with $40 \pm 9 \%$, while glucose reduction led to similar results in HT1080 and Huh7 ( $20 \pm 4 \%$ and $22 \pm 6 \%$ ). Starving did not significantly enhance metabolism beyond 2-[ $\left.{ }^{18} \mathrm{~F}\right] \mathrm{FDG}$ in Huh7 or HT29 compared to glucose-reduced conditions. However, $2 \mathrm{~h}$ starving significantly enhanced radiometabolite formation in HT1080 to $34 \pm 12 \%$ ( $p \leq 0.001$ compared to glucose conditions).

In summary, glucose withdrawal led to increased intracellular 2- $\left[{ }^{18} \mathrm{~F}\right] \mathrm{FDG}$ accumulation and enhanced radiometabolite formation dependent on the cell line.

Table 1 gives a more detailed overview on the change of radiometabolite formation dependent on the glucose concentration. In general, the most prominent radiometabolites rising when glucose in the medium was reduced were 2- $\left[{ }^{18} \mathrm{~F}\right] \mathrm{FDG}-1-\mathrm{P}, 2-\left[{ }^{18} \mathrm{~F}\right] \mathrm{FDM}-6-\mathrm{P}$ and 2- $\left[{ }^{18} \mathrm{~F}\right]$ FD-PGL. In contrast to that, besides parent 2- $\left[{ }^{18} \mathrm{~F}\right] \mathrm{FDG}$ and $2-\left[{ }^{18} \mathrm{~F}\right] \mathrm{FDG}-6-\mathrm{P}$, levels of $2-\left[{ }^{18} \mathrm{~F}\right] \mathrm{FDG}-1,6-\mathrm{P}_{2}$ decreased under glucose deprivation. HT29 was the only cell line with noteworthy radiometabolite formation beyond 2-[ $\left.{ }^{18} \mathrm{~F}\right] \mathrm{FDG}-6-\mathrm{P}$ under glucose conditions and also the cell line with the highest $2-\left[{ }^{18} \mathrm{~F}\right] \mathrm{FD}-\mathrm{PGL}$ formation under glucose $(3 \pm 1 \%)$ and glucose-reduced $(15 \pm 7 \%)$ conditions. 
Table 1. Mean radiometabolite formation (\%) under different conditions in HT1080, HT29 and Huh7. Conditions: glucose $=1.13 \mathrm{~g} / \mathrm{L}$, glucose-reduced $=0.13 \mathrm{~g} / \mathrm{L}$, starve $=$ glucose-reduced medium 1 or $2 \mathrm{~h}$ prior to $2-\left[{ }^{18} \mathrm{~F}\right] \mathrm{FDG}$ addition . Radiometabolites at $\sim 6, \sim 22, \sim 23.5$ and $\sim 27 \mathrm{~min}$ were excluded due to their negligible formation.

\begin{tabular}{|c|c|c|c|c|c|c|c|c|c|}
\hline \multirow{3}{*}{ Radiometabolites } & \multirow{3}{*}{ RT (min) } & \multicolumn{8}{|c|}{ HT1080 } \\
\hline & & \multicolumn{2}{|c|}{ Glucose } & \multicolumn{2}{|c|}{ Glucose-Reduced } & \multicolumn{2}{|c|}{ Starve $(1 \mathrm{~h})$} & \multicolumn{2}{|c|}{ Starve (2 h) } \\
\hline & & mean $(\%)$ & SD & mean $(\%)$ & SD & mean $(\%)$ & SD & mean $(\%)$ & SD \\
\hline $2-\left[{ }^{18} \mathrm{~F}\right] \mathrm{FDG}$ & $\sim 4$ & 11 & 3 & 0.3 & 0.1 & 0.40 & 0.09 & 0.62 & 0.28 \\
\hline $2-\left[{ }^{18} \mathrm{~F}\right]$ FDG-1-P & $\sim 7$ & 0 & 0 & 1.6 & 0.7 & 3.18 & 2.61 & 5.7 & 3.5 \\
\hline $2-\left[{ }^{18} \mathrm{~F}\right] F D G-6-P$ & $\sim 9.5$ & 79 & 2 & 79 & 4 & 78 & 9 & 66 & 12 \\
\hline $2-\left[{ }^{18} \mathrm{~F}\right]$ FDM-6-P & $\sim 12$ & 0 & 0 & 9 & 5 & 6 & 5 & 12 & 1 \\
\hline radiometabolite 5 & $\sim 19.5$ & 0 & 0 & 0.53 & 0.44 & 0.56 & 0.25 & 2 & 1 \\
\hline UDP-2-[ $\left[{ }^{18} \mathrm{~F}\right] \mathrm{FDG}$ & $\sim 21$ & 0 & 0 & 0.51 & 0.23 & 0.69 & 0.40 & 1.7 & 0.8 \\
\hline $2-\left[{ }^{18} \mathrm{~F}\right] \mathrm{FD}-\mathrm{PGL}$ & $\sim 25$ & 0.0 & 0.0 & 4 & 2 & 7 & 4 & 12 & 7 \\
\hline $2-\left[{ }^{18} \mathrm{~F}\right] \mathrm{FDG}-1,6-\mathrm{P}_{2}$ & $\sim 28$ & 8 & 2 & 3 & 2 & 3 & 2 & 0.47 & 0.11 \\
\hline \multirow[t]{2}{*}{ radiometabolite 12} & $\sim 29.5$ & 1.1 & 0.6 & 0.95 & 0.60 & 0.96 & 0.82 & 0.22 & 0.02 \\
\hline & & \multicolumn{8}{|c|}{ HT29 } \\
\hline \multirow{2}{*}{ Radiometabolites } & \multirow{2}{*}{ RT (min) } & \multicolumn{2}{|c|}{ Glucose } & \multicolumn{2}{|c|}{ Glucose-Reduced } & \multicolumn{2}{|c|}{ Starve (1 h) } & \multicolumn{2}{|c|}{ Starve (2 h) } \\
\hline & & mean $(\%)$ & SD & mean $(\%)$ & SD & mean $(\%)$ & SD & mean $(\%)$ & SD \\
\hline $2-\left[{ }^{18} \mathrm{~F}\right] \mathrm{FDG}$ & $\sim 4$ & 3 & 1 & 0.4 & 0.2 & 0.57 & 0.14 & 0.4 & 0.1 \\
\hline $2-\left[{ }^{18} \mathrm{~F}\right]$ FDG-1-P & $\sim 7$ & 1.2 & 0.5 & 3 & 1 & 3 & 2 & 1.2 & 0.2 \\
\hline $2-\left[{ }^{18} \mathrm{~F}\right]$ FDG-6-P & $\sim 9.5$ & 79 & 4 & 59 & 9 & 56 & 10 & 69.0 & 0.7 \\
\hline $2-\left[{ }^{18} \mathrm{~F}\right]$ FDM-6-P & $\sim 12$ & 7 & 2 & 14 & 3 & 17 & 3 & 19 & 1 \\
\hline radiometabolite 5 & $\sim 19.5$ & 0.1 & 0.1 & 1.5 & 0.9 & 2.9 & 1.0 & 2.2 & 0.4 \\
\hline UDP-2-[ $\left[{ }^{18} \mathrm{~F}\right] \mathrm{FDG}$ & $\sim 21$ & 0.1 & 0.2 & 1.0 & 0.6 & 2.1 & 0.5 & 2.0 & 0.3 \\
\hline 2-[$\left[{ }^{18} \mathrm{~F}\right]$ FD-PGL & $\sim 25$ & 3 & 1 & 15 & 7 & 15 & 8 & 5 & 2 \\
\hline $2-\left[{ }^{18} \mathrm{~F}\right] \mathrm{FDG}-1,6-\mathrm{P}_{2}$ & $\sim 28$ & 4 & 3 & 3 & 3 & 1 & 1 & 0.3 & 0.1 \\
\hline \multirow[t]{2}{*}{ radiometabolite 12} & $\sim 29.5$ & 3 & 1 & 3 & 1 & 2 & 1 & 0.7 & 0.2 \\
\hline & & \multicolumn{8}{|c|}{ Huh7 } \\
\hline \multirow{2}{*}{ Radiometabolites } & \multirow{2}{*}{ RT (min) } & \multicolumn{2}{|c|}{ Glucose } & \multicolumn{2}{|c|}{ Glucose-reduced } & \multicolumn{2}{|c|}{ Starve $(1 \mathrm{~h})$} & \multicolumn{2}{|c|}{ Starve $(2 \mathrm{~h})$} \\
\hline & & mean $(\%)$ & SD & mean $(\%)$ & SD & mean $(\%)$ & SD & mean $(\%)$ & SD \\
\hline $2-\left[{ }^{18} \mathrm{~F}\right] \mathrm{FDG}$ & $\sim 4$ & 8 & 2 & 2 & 1 & 3 & 2 & 2 & 1 \\
\hline $2-\left[{ }^{18} \mathrm{~F}\right]$ FDG-1-P & $\sim 7$ & 0.7 & 0.4 & 4 & 2 & 3 & 2 & 4 & 2 \\
\hline $2-\left[{ }^{18} \mathrm{~F}\right]$ FDG-6-P & $\sim 9.5$ & 86 & 3 & 76 & 6 & 76 & 5 & 77 & 6 \\
\hline $2-\left[{ }^{18} \mathrm{~F}\right]$ FDM-6-P & $\sim 12$ & 4 & 2 & 13 & 4 & 10 & 6 & 8 & 5 \\
\hline radiometabolite 5 & $\sim 19.5$ & 0.2 & 0.3 & 0.5 & 0.3 & 1.5 & 0.5 & 2 & 1 \\
\hline UDP-2-[ $\left[{ }^{18} \mathrm{~F}\right] \mathrm{FDG}$ & $\sim 21$ & 0.1 & 0.2 & 1.1 & 0.5 & 1.8 & 0.7 & 2.7 & 1.0 \\
\hline $2-\left[{ }^{18} \mathrm{~F}\right] \mathrm{FD}-\mathrm{PGL}$ & $\sim 25$ & 0.4 & 0.8 & 3 & 1 & 3.4 & 0.8 & 3 & 2 \\
\hline $2-\left[{ }^{18} \mathrm{~F}\right] F D G-1,6-\mathrm{P}_{2}$ & $\sim 28$ & 0.7 & 0.3 & 0.2 & 0.2 & 0.1 & 0.1 & 0.4 & 0.1 \\
\hline radiometabolite 12 & $\sim 29.5$ & 0.2 & 0.2 & 0.1 & 0.2 & 0.06 & 0.07 & 0.2 & 0.2 \\
\hline
\end{tabular}

Building on Table 1, we analyzed our HPLC data with a graphical Gaussian model to identify and illustrate relevant correlations between radiometabolite formation under different glucose conditions (Figure 4). In accordance with Table 1, the graphical Gaussian model demonstrates that the cell lines handle 2- $\left[{ }^{18} \mathrm{~F}\right] \mathrm{FDG}$ differently dependent on glucose concentration. Overall, positive partial correlations between radiometabolite formation under different conditions were particularly pronounced in Huh7, while they were the least pronounced in HT29. However, the highest positive partial correlation was observed between glucose-reduced (gluc-red) and starve ( 1 h) conditions in HT29, with a value of 0.73 . 

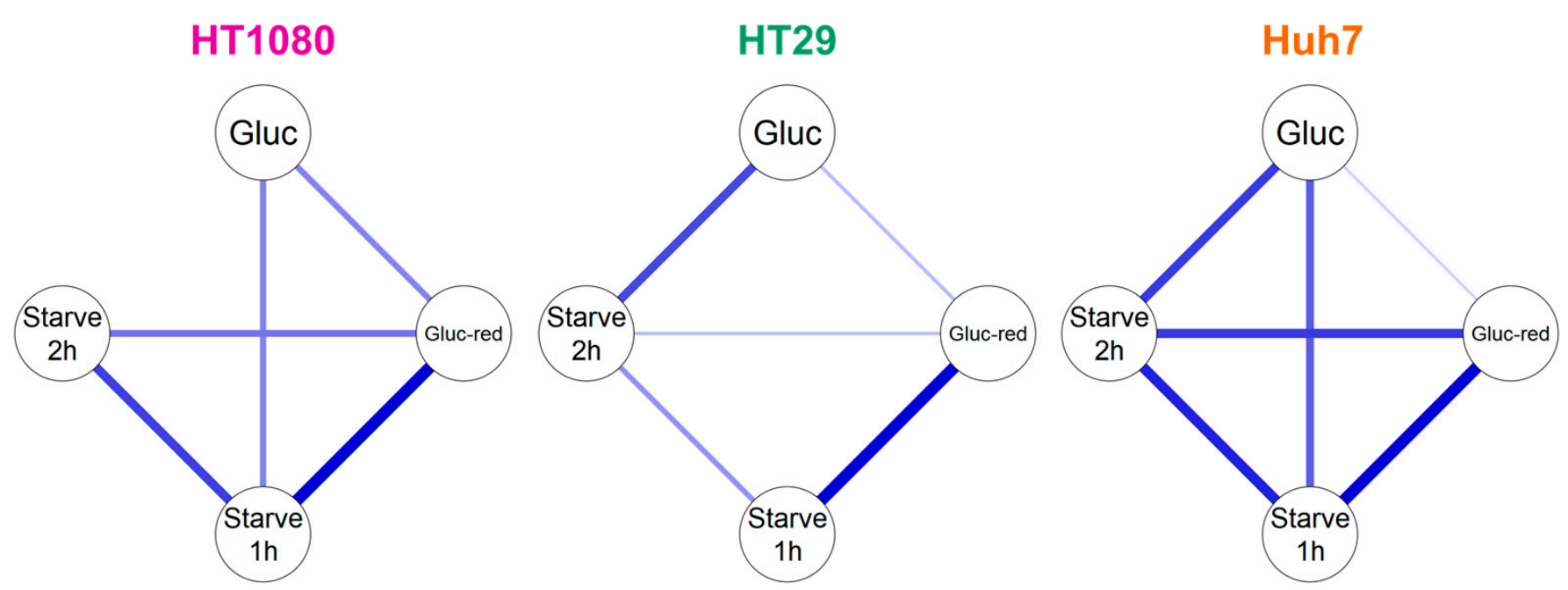

Figure 4. Graphical Gaussian model of 2-[18F]FDG metabolism in HT1080, HT29 and Huh7. Blue lines show positive correlations. The thicker the line, the higher the correlation.

\subsection{Efflux of Radioactivity in HT1080 (Fibrosarcoma) and HT29 (Colorectal Adenocarcinoma)}

In general, as expected, $2-\left[{ }^{18} \mathrm{~F}\right] \mathrm{FDG}$ was the most prominent compound when analyzing the supernatant with HPLC, $1 \mathrm{~h}$ after medium change. However, $2-\left[{ }^{18} \mathrm{~F}\right] \mathrm{FDM}$ and $2-\left[{ }^{18} \mathrm{~F}\right] \mathrm{FDG}-6-\mathrm{P}$ could be detected additionally under glucose conditions and 2- $\left[{ }^{18} \mathrm{~F}\right] \mathrm{FDM}$, 2-[ $\left.{ }^{18} \mathrm{~F}\right]$ FDG-1-P, 2- $\left[{ }^{18} \mathrm{~F}\right]$ FDG-6-P and 2-[ $\left.{ }^{18} \mathrm{~F}\right]$ FD-PGL when glucose content was reduced. In HT1080 cells, levels of extracellular radiometabolites were higher than in HT29, both under glucose or glucose-reduced conditions (Figure 5A). Under glucose-reduced conditions, levels of extracellular radiometabolites were significantly elevated in both cell lines $1 \mathrm{~h}$ after medium change.

A

Efflux: Radiometabolites in the supernatant

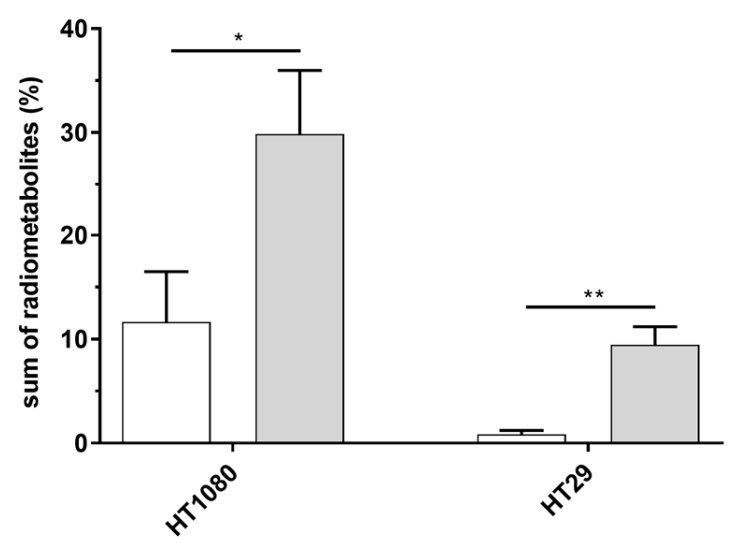

B

Efflux: Total radioactivity in the supernatant

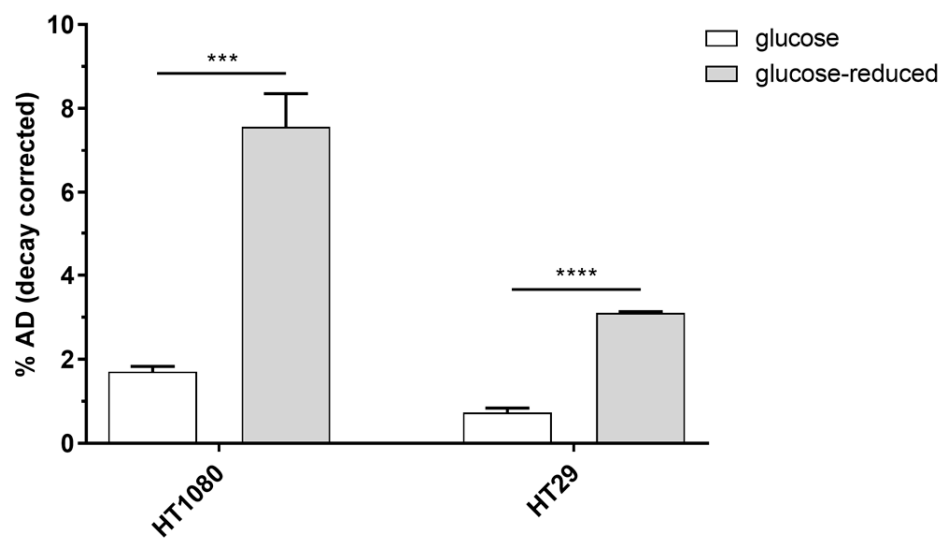

Figure 5. Sum of radiometabolites (\%) detected with HPLC (A) and total radioactivity in \% applied dose (\% AD) in supernatants of HT1080 and HT29 $1 \mathrm{~h}$ after change to non-radioactive medium $(\mathbf{B})\left({ }^{*} p \leq 0.05,{ }^{* *} p \leq 0.01,{ }^{* * *} p \leq 0.001\right.$ and $* * * * p \leq 0.0001$ ). Conditions: glucose $=1.13 \mathrm{~g} / \mathrm{L}$, glucose-reduced $=0.13 \mathrm{~g} / \mathrm{L}$.

Quantifying radioactivity in the supernatant $1 \mathrm{~h}$ after the change to non-radioactive medium, decay-corrected amounts were $1.7 \pm 0.1 \% \mathrm{AD}$ (glucose) and $7.6 \pm 0.8 \% \mathrm{AD}$ (glucose-reduced) for HT1080 and $0.7 \pm 0.1 \% \mathrm{AD}$ (glucose) and $3.1 \pm 0.3 \% \mathrm{AD}$ (glucosereduced) for HT29 (Figure 5B). 
In the lactate dehydrogenase (LDH) assay, no change of extracellular LDH activity was seen in the supernatants between time-point 1 (before medium change) and time-point 2 ( $1 \mathrm{~h}$ after medium change) (Figure S1), indicating no leakage of cell membranes.

\section{Discussion}

Rokka et al. [18] presented a suitable radio-HPLC assay for the analysis of 2- $\left[{ }^{18} \mathrm{~F}\right] \mathrm{FDG}$ metabolism identifying the radiometabolites 2- $\left[{ }^{18} \mathrm{~F}\right]$ FDG-6-P, $2-\left[{ }^{18} \mathrm{~F}\right] \mathrm{FDG}-1,6-\mathrm{P}_{2}$ and 2$\left[{ }^{18} \mathrm{~F}\right] \mathrm{FD}-\mathrm{PGL}$. Building on their assay, we additionally verified the formation of the radiometabolites 2- $\left[{ }^{18}\right.$ F]FDG-1-P, 2- $\left[{ }^{18}\right.$ F]FDM-6-P and UDP-2- $\left[{ }^{18}\right.$ F]FDG. In particular, the formation of FDM-6-P was described in several 19F-NMR studies with FDG before [11-13,21]. It was postulated that while building an analogue of fructose-6-phosphate is prevented by the fluoride, the formation of 1,2-endiol as an intermediate and lastly FDM-6-P is still possible [22]. However, to the best of our knowledge, we are the first to verify the intracellular formation of 2- $\left[{ }^{18} \mathrm{~F}\right] \mathrm{FDM}-6-\mathrm{P}$, as well as of the other radiometabolites $2-\left[{ }^{18} \mathrm{~F}\right] \mathrm{FDG}-1-\mathrm{P}$ and UDP-2- $\left[{ }^{18} \mathrm{~F}\right]$ FDG using the radiotracer $2-\left[{ }^{18} \mathrm{~F}\right] \mathrm{FDG}$. Furthermore, despite what is often stated [16,23], 2-[18 F]FDG-6-P seems to also be processed by G6PD and not only H6PD, at least in a cell-free assay in vitro, as already proposed by Suolinna et al. [14].

Looking at the accumulation experiments, glucose reduction to one tenth led to an increase in 2- $\left[{ }^{18} \mathrm{~F}\right] \mathrm{FDG}$ uptake of around 24 times in Huh7, 130 times in HT29 and 150 times in HT1080, although the same amount of radioactivity was used. The comparatively little difference within Huh7 might be rooted in using MEM for the accumulation experiments under glucose conditions. As Huh7 was cultivated in high-glucose DMEM, the change to MEM already resulted in a large glucose reduction for these cells $(4.63 \mathrm{~g} / \mathrm{L}$ to $1.13 \mathrm{~g} / \mathrm{L})$. This might also explain why there was a smaller difference of extracellular lactate concentration between glucose and glucose-reduced conditions in this cell line as compared to HT1080 and HT29.

Our efflux experiments showed that radiometabolites can be found in the cell culture medium $1 \mathrm{~h}$ after change to non-radioactive medium. Although the results of the LDH assay indicate no leakage of cell membranes, the $2-\left[{ }^{18} \mathrm{~F}\right] \mathrm{FDG}$ accumulation experiments were generally performed in fully supplemented cell culture medium with inherent LDH activity. Therefore, the background was high and small changes in LDH excretion might therefore be hard to detect. Moreover, the LDH assay determines the activity of the enzyme, not the mere presence of it. Hence, in contrast to HPLC measurements of radiometabolites, the results of this assay are subject to many influences and results should therefore be interpreted with caution. Moreover, up to this date, the only known transporters for sugarphosphates are located at the membranes of intracellular microsomes [24], making a sugar phosphate transport out of the cell unlikely. Still, extracellular phosphorylated 2-[ ${ }^{18}$ F]FDG metabolite levels and total radioactivity in the supernatant after the efflux experiment were significantly higher in HT1080, both under glucose and glucose-reduced conditions. Interestingly, the intracellular levels of phosphorylated radiometabolites beyond 2-[ $\left.{ }^{18} \mathrm{~F}\right] \mathrm{FDG}-6-\mathrm{P}$ were around twice as high in HT29 compared to HT1080 after $1 \mathrm{~h}$ (glucose: 18 vs. 9\%; glucose-reduced or starved: $\sim 40$ vs. $\sim 20 \%$ ). Hence, there is less efflux in the cell line that shows higher metabolism. Cossu et al. suggested that the dephosphorylating enzyme G6Pase and H6PD compete for 2- $\left[{ }^{18} \mathrm{~F}\right] \mathrm{FDG}-6-\mathrm{P}$ in the ER [25]. Thus, enhanced production of 2-[ ${ }^{18}$ F]FDG-PGL by H6PD would significantly reduce dephosphorylation and subsequent efflux of $2-\left[{ }^{18} \mathrm{~F}\right] \mathrm{FDG}$, which would at least explain higher extracellular 2-[18 F]FDG levels of HT1080.

The main focus of this paper, however, was to investigate whether a specific pattern of 2- $\left[{ }^{18} \mathrm{~F}\right]$ FDG metabolism could be observed in different human cancer cell lines, under different glucose concentrations. In comparison to Rokka et al. we could in general detect more radiometabolites with HPLC analysis. However, compared to our cell assay, where we applied relatively high activities $(1 \mathrm{MBq} / \mathrm{mL})$, they analyzed tissue samples of rats and mice [18]. Hence, due to biodistribution and subsequent work steps such as organ removal and processing (homogenization, dilution), radioactivity in their samples was 
most likely lower. Moreover, we saw the highest amounts of radiometabolites when we reduced glucose concentration in the medium. This set-up cannot be applied in an in vivo experiment.

Although the three tumor cell lines were derived from very different tumor entities (fibrosarcoma, colorectal adenocarcinoma, hepatocellular carcinoma), which in turn originate from different cell types, the radiometabolites generated were almost identical. Interestingly, we saw differences regarding the extent of radiometabolite formation and the cells' response to glucose reduction or starving (Table 1), suggesting different 2-[ ${ }^{18}$ F]FDG handling. This was further supported by our graphical Gaussian model, an established mathematical model for network analysis of biological systems [26,27] that we applied to visualize correlations (Figure 4).

We found that-except for HT29-metabolism beyond 2-[18F]FDG-6-P was not pronounced under glucose conditions (baseline). However, the extent of $2-\left[{ }^{18} \mathrm{~F}\right] \mathrm{FDG}$ metabolism and especially radiometabolites reflecting glycogen metabolism (2-[ $\left.{ }^{18} \mathrm{~F}\right] \mathrm{FDG}-1-$ P) or the PPP (2- $\left.\left[{ }^{18} \mathrm{~F}\right] \mathrm{FD}-\mathrm{PGL}\right)$ rose under glucose reduction. This fact matches the cells metabolic switch under glucose reduction as displayed by reduced extracellular lactate levels. Glucose withdrawal is also known to cause a stress situation for glucose-dependent cancer cells [28,29]. Cancer cells can use glycogen metabolism [28] or the PPP [30]-both interconnecting with key metabolic pathways such as glycolysis-to counterbalance (oxidative) stress and sustain growth. Furthermore, we observed enhanced 2-[ $\left.{ }^{18} \mathrm{~F}\right] \mathrm{FDM}-6-\mathrm{P}$ formation when glucose content was reduced. Interestingly, McSheehy et al. showed in a study with cold FDG and 5-fluorouracil that generated FDM and its phosphorylated conjugates were representative for the treatment response to 5-fluorouracil in mice [21], emphasizing the potential of analyzing FDG metabolism.

Although we present in vitro data from established cancer cell lines, we propose that glucose availability could also have substantial influence on the uptake and metabolism of $2-\left[{ }^{18} \mathrm{~F}\right]$ FDG in vivo. While Sprinz et al. postulate that the influence of blood glucose levels on 2-[ $\left.{ }^{18} \mathrm{~F}\right]$ FDG uptake in normal organs and tumors is negligible [31], other publications report false-negative 2-[ ${ }^{18}$ F]FDG tumor PET-scans due to hyperglycemia [32-34]. They also highlight the importance of fasting prior to the PET-scan [32]. A fasting period of at least $4 \mathrm{~h}$ is also recommended in the latest version of the tumor PET/CT guidelines of the European Association of Nuclear Medicine [35].

Furthermore, on a cellular level, factors like tumor vascularization, lymphatics or competition for nutrients with microenvironmental cells can substantially influence nutrient accessibility for tumor cells [36] and could thus influence $2-\left[{ }^{18}\right.$ F]FDG handling locally.

\section{Materials and Methods}

\subsection{General}

2-[ ${ }^{18}$ F]FDG was synthesized in-house in a fully automated cassette-based module (FASTlab, GE Healthcare, Uppsala, Sweden) at the Vienna General Hospital, Austria and was applied to the cells after quality control, formulated for patient use. All chemicals were purchased from Merck KGaA (Darmstadt, Germany) and all consumables or cell culture supplies were bought from known suppliers, such as VWR International (Radnor, PA, USA), Merck KGaA or Thermo Fisher Scientific Inc. (Waltham, MA, USA).

\subsection{Cell Culture}

The human fibrosarcoma cell line HT1080 was kindly provided by the Institute of Inorganic Chemistry, University of Vienna. HT1080 was grown in MEM with the addition of 10\% FBS and $2 \mathrm{mM}$ L-glutamine. The human colorectal adenocarcinoma cell line HT29 was a generous gift from the Department of Pathology, Medical University of Vienna. This cell line was grown in Roswell Park Memorial Institute Medium (RPMI-1640) supplemented with 10\% FBS and 2 mM L-glutamine. The human hepatocellular carcinoma cell line Huh7 was kindly provided by Dr. Nataliya Rohr-Udilova, Division of Gastroenterology and 
Hepatology, Medical University of Vienna. Huh7 cells were grown in high-glucose DMEM with $4 \mathrm{mM}$ L-glutamine, complemented with $10 \%$ FBS.

All cells were kept in a humidified incubator $\left(37^{\circ} \mathrm{C}, 5 \% \mathrm{CO}_{2}\right)$ at the Department of Biomedical Imaging and Image-guided Therapy.

For experiments, we used either fully supplemented MEM or glucose-free DMEM supplemented with $10 \%$ fetal bovine serum (FBS). FBS has an average glucose content of $125 \mathrm{mg} / 100 \mathrm{~mL}$ [37]. Supplementation therefore results in an average concentration of $0.13 \mathrm{~g} / \mathrm{L}$ as compared to a glucose concentration of around $1.13 \mathrm{~g} / \mathrm{L}$ in fully supplemented MEM that we used for "glucose" experiments. Glucose content was therefore reduced to approximately one tenth. For starving experiments, glucose-reduced DMEM was already applied to the cells 1 or $2 \mathrm{~h}$ prior to $2-\left[{ }^{18} \mathrm{~F}\right] \mathrm{FDG}$ addition.

\subsection{Enzymatic In Vitro Synthesis of $2-\left[{ }^{18} F\right] F D G$ Radiometabolites}

In general, reference radiometabolites were prepared via enzymatic in vitro synthesis on the basis of previously published procedures by Rokka et al. [18] and Kaarstadt et al. [15] (Figure 1). After centrifugation $\left(22^{\circ} \mathrm{C}, 13,684 \mathrm{~g}\right)$, the reaction mixes were analyzed with HPLC as described for the cell samples.

\section{4. $2-\left[{ }^{18} F\right] F D G-6-P$}

Around $20 \mathrm{MBq} 2-\left[{ }^{18} \mathrm{~F}\right] \mathrm{FDG}$ was added to a phosphate buffered saline (PBS) solution containing $100 \mu \mathrm{L}$ hexokinase, $2 \mathrm{mg}$ adenosine triphosphate (ATP) and $1 \mathrm{mg}$ magnesium chloride. The $\mathrm{pH}$ was adjusted to $7-7.5$ with $1 \mathrm{M}$ sodium hydroxide $(\mathrm{NaOH})$. The mixture was mixed in a shaker (Eppendorf, Hamburg, Germany) for $2 \mathrm{~h}$ at $37^{\circ} \mathrm{C}$.

\section{5. $\left.2-{ }^{18} F\right] F D-P G L$}

After synthesis of 2- $\left[{ }^{18} \mathrm{~F}\right] \mathrm{FDG}-6-\mathrm{P}, 4.5 \mathrm{mg} \beta$-nicotinamide adenine dinucleotide phosphate and 35 units of G6PD (from yeast or leuconostoc mesenteroides) were added. The solution was again incubated at $37^{\circ} \mathrm{C}$ for $2.5 \mathrm{~h}$.

\section{6. $\left.2-{ }^{18} F\right] F D G-1,6-P_{2}$}

In that case, the 2- $\left[{ }^{18} \mathrm{~F}\right]$ FDG-6-P solution was further processed with 20 units PGM, $1 \mathrm{mg} \alpha$-D-glucose-1,6-diphosphate cyclohexylammonium salt, $1 \mathrm{mg}$ EDTA and $1.3 \mathrm{mg}$ BSA. The $\mathrm{pH}$ was adjusted to around 7.9 with $1 \mathrm{M} \mathrm{NaOH}$. The mixture was again shaken at $37^{\circ} \mathrm{C}$ for $2.5 \mathrm{~h}$.

\section{7. $\left.2-{ }^{18} F\right] F D G-1-P$}

This metabolite was detected after $2 \mathrm{~h}$, when synthesizing $2-\left[{ }^{18} \mathrm{~F}\right] \mathrm{FDG}-1,6-\mathrm{P}_{2}$ under suboptimal conditions $(\mathrm{pH}<7.9)$.

\subsection{UDP-2-[ $\left.{ }^{18} F\right] F D G$}

After synthesis of 2- $\left[{ }^{18} \mathrm{~F}\right] \mathrm{FDG}-6-\mathrm{P}$, the solution was filtered with a Centrifree Ultrafiltration Device with Ultracel PL membrane (cutoff $30 \mathrm{kDa}$, Merck KGaA, Darmstadt, Germany) by centrifugation at $1520 \times g(15 \mathrm{~min}, \mathrm{RT})$ in order to remove hexokinase $(\sim 100 \mathrm{kDa})$. Then, 20 units PGM, $2 \mu \mathrm{mol}$ UTP and 10 units UGPase were added for $3 \mathrm{~h}$.

\section{9. $2-\left[{ }^{18} F\right] F D M-6-P$}

As PBS can hamper the activity of phosphoglucose isomerase (PGI) according to the supplier, another batch of 2-[ $\left.{ }^{18} \mathrm{~F}\right]$ FDG-6-P was produced in HEPES buffered saline solution ( $\mathrm{pH}$ 7.5). After the formation of 2-[ $\left.{ }^{18} \mathrm{~F}\right]$ FDG-6-P was confirmed, 200 units of PGI were added to synthesize 2- $\left[{ }^{18} \mathrm{~F}\right] \mathrm{FDM}-6-\mathrm{P}$. The mixture was incubated at $37^{\circ} \mathrm{C}$ for another $3 \mathrm{~h}$. 


\subsection{0. $2-\left[{ }^{18} F\right] F D G$ Accumulation Experiments}

The workflow for accumulation experiments is shown in Figure 2. Cells were seeded into 6-well plates two days prior, reaching $80-90 \%$ confluency on the day of the experiment. For the experiment, growth medium was withdrawn and cells were washed once with the respective medium, before fully supplemented MEM or glucose-reduced DMEM were added, containing $1 \mathrm{MBq} / \mathrm{mL} 2-\left[{ }^{18} \mathrm{~F}\right] \mathrm{FDG}(n=5)$. Then, $1 \mathrm{~h}$ after addition of $2-$ $\left[{ }^{18} \mathrm{~F}\right] \mathrm{FDG}$, aliquots of the supernatants were taken, cells were washed two times with PBS, detached with $500 \mu \mathrm{L}$ of Accutase and resuspended in MEM. A $100 \mu \mathrm{L}$ aliquot of the cell suspension was measured with a gamma counter (PerkinElmer, 2480 Automatic Gamma counter, Wizard23) and subsequently, cells were mixed with trypan blue and counted with a Neubauer chamber. Values are expressed as \% applied dose (\% AD) per $10^{4}$ cells.

The aliquots of the supernatants were filtered through a Microcon- $30 \mathrm{kDa}$ Centrifugal Filter Unit (Merck KGaA, Darmstadt, Germany) to remove LDH from the medium. Then, lactate concentration was determined with a lactate assay kit (Merck KGaA, Darmstadt, Germany) following the supplier's instructions.

\subsection{Radiometabolite Detection with HPLC}

While we used one of the anion-exchanger columns applied by Rokka et al. [18] for radiometabolite separation, we used a different HPLC system and a different experimental setup. The HPLC method by Rokka et al. [18] was therefore adapted to our system for an optimal separation of the peaks by changing the gradient profile and the run time (Table S1). The final gradient profile of solvent A ( $0.6 \mathrm{M}$ sodium dihydrogen phosphate buffer with 3\% methanol) and B (3\% methanol in water) was 0-12 min 5\% A, 13 min $10 \% \mathrm{~A}$, 14-18 $\min 15 \%$ A, $19-32 \min 50 \%$ A and $34-35 \min 5 \%$ A. Table S1 shows a comparison between the HPLC method by Rokka et al. [18] and our method.

Figure 2 shows the workflow of HPLC experiments to determine intracellular radiometabolite formation. 2-[ $\left.{ }^{18} \mathrm{~F}\right] \mathrm{FDG}$ was applied under glucose conditions, glucosereduced conditions or 1 or $2 \mathrm{~h}$ starving (addition of glucose-reduced DMEM prior to $\left.2-\left[{ }^{18} \mathrm{~F}\right] \mathrm{FDG}\right)$. In general, cells were seeded, treated and washed as described for the accumulation experiments ( $n \geq 9$ except for $2 \mathrm{~h}$ starve, where $n=7$ (HT1080), 6 (Huh7) and 3 (HT29)). However, cells were not detached with Accutase, but lysed with $250 \mu \mathrm{L}$ of methanol $(\mathrm{MeOH})$ and scratched off the surface with a cell scraper. Lysates were then centrifuged for $4 \mathrm{~min}\left(4^{\circ} \mathrm{C}, 13,684 \mathrm{~g}\right)$ and supernatants were subsequently injected into an HPLC system (Agilent Technologies, Santa Clara, CA, USA) with a radio detector (Ramona, Elysia-Raytest, Straubenhardt, Germany) and a cooled sample table. Radiometabolites were separated with an anion-exchanger Partisil ${ }^{\mathrm{TM}} 10 \mathrm{SAX}$ column $(250 \mathrm{~mm} \times 4.6 \mathrm{~mm}$, Supelco ${ }^{\circledR}$ analytical, PA, USA) with a flow of $1 \mathrm{~mL} / \mathrm{min}$. Chromatograms were subsequently evaluated with the software GINA Star ${ }^{\mathrm{TM}}$ (Version 5.9 Service Pack 17, Ramona, Elysia-Raytest, Straubenhardt, Germany).

The limit of detection was defined as three times and the limit of quantification as at least five times the area under the curve of the background area as described by González, O., \& Alonso, R. M. [38]. The results presented in this article were corrected for the background area by manual integration of the peaks of interest. For every chromatogram the background was quantified separately.

\subsection{Efflux Experiments}

2- $\left[{ }^{18} \mathrm{~F}\right]$ FDG was applied to the cells in either MEM or glucose-reduced DMEM as described above. Then, $1 \mathrm{~h}$ after $2-\left[{ }^{18} \mathrm{~F}\right] \mathrm{FDG}$ addition, the supernatant was withdrawn and cells were washed three times with fresh medium, before $1.5 \mathrm{~mL}$ of new, non-radioactive medium (MEM or DMEM) was added carefully. After $1 \mathrm{~h}, 500 \mu \mathrm{L}$ of the supernatant was collected, centrifuged at $13,684 \mathrm{~g}$ and injected into HPLC ( $n=3$ each). Another aliquot was measured in the gamma counter to quantify extracellular radioactivity. Values are again expressed as \% AD (decay corrected). To ensure that the cell membranes were still intact after the washing steps and medium changes, aliquots of the supernatants were taken 
before the washing steps and at the end of the efflux experiments to determine extracellular LDH activity with an LDH assay kit (Thermo Fisher Scientific Inc., Waltham, MA, USA) according to the supplier's instructions.

\subsection{Statistics}

\subsubsection{General}

The values are depicted as mean \pm SD. All experiments were performed in triplicate (or in duplicate in the case of radiometabolite analysis after $1 \mathrm{~h}$ ) and repeated at least three times. Two-sided $t$-tests were performed with the software Prism 7.03 (GraphPad, San Diego, CA, USA) and $p$-values $\leq 0.05$ were considered statistically significant.

\subsubsection{Gaussian Model}

For a further analysis of the metabolic pattern, a network analysis was performed with a graphical Gaussian model as recently described [27] using JASP software (JASP Team, Version 0.14.1, https: / /jasp-stats.org/, accessed on 7 June 2021). This analysis uses partial correlation, i.e., the correlation between the residuals resulting from linear regression, as a measure of independence between two data points, allowing us to distinguish between direct and indirect interactions. Line thickness indicates the strength of the positive partial correlation. A detailed description of the Gaussian network model theory can also be found in the Supplementary Materials of Perišić et al. [39].

\section{Conclusions}

Overall, we could show that the extent of $2-\left[{ }^{18} \mathrm{~F}\right]$ FDG metabolism is not the same in different cancer cell lines and that glucose deprivation significantly enhances radiometabolite formation and total intracellular accumulation dependent on the cell line. Building on the publication by Kernstine K.H. et al., suggesting that 2- $\left[{ }^{18}\right.$ F]FDG PET predicts the use of glucose in pathways other than glycolysis [7], we claim that 2-[18 F]FDG metabolism can be an important readout for the cells' metabolic (re-)wiring. From a translational point of view and bearing in mind that $2-\left[{ }^{18} \mathrm{~F}\right] \mathrm{FDG}$ radiometabolites could be an important readout for tumor heterogeneity, we need to have a closer look at the biological processes involved. Instead of simple static quantifications of 2-[ $\left.{ }^{18} \mathrm{~F}\right] \mathrm{FDG}$ uptake at single timepoints, the kinetic behavior of $2-\left[{ }^{18} \mathrm{~F}\right] \mathrm{FDG}$ in each voxel over time should be assessed. New imaging technologies for whole-body PET combined with kinetic modelling and parametric analysis of the given images over time could provide an important toolset for this methodological challenge.

Supplementary Materials: The following are available online at https: / www.mdpi.com/article/ 10.3390/ph14090910/s1, Figure S1: LDH activity in the supernatants of HT1080 and HT29, $1 \mathrm{~h}$ after changing the medium., Table S1: Comparison between the HPLC method of Rokka et al. [18] and our adapted method.

Author Contributions: E.-M.K. and M.M. (Mahshid Mahmudi) performed the experiments. B.K.G., V.P., C.V. and T.B. helped design the experiments and analyze the data. E.-M.K., B.K.G. and M.M. wrote the manuscript. A.M., A.H., H.V., N.R.-U., M.H. and M.M. (Markus Mitterhauser) helped with data interpretation and reviewed the manuscript. All authors have read and agreed to the published version of the manuscript.

Funding: This research received no external funding.

Institutional Review Board Statement: Not applicable.

Informed Consent Statement: Not applicable.

Data Availability Statement: Data is contained within the article and supplementary files.

Acknowledgments: We thank Katharina Pallitsch for her efforts related to metabolite detection and Wolfgang Wadsak for constructive discussions. Furthermore, we are grateful for the support of the Medical Imaging Cluster (MIC) of the Medical University of Vienna. 
Conflicts of Interest: The authors declare no conflict of interest.

\section{References}

1. Wadsak, W.; Mitterhauser, M. Basics and principles of radiopharmaceuticals for PET/CT. Eur. J. Radiol. 2010, 73, 461-469. [CrossRef]

2. Pichler, V.; Berroterán-Infante, N.; Philippe, C.; Vraka, C.; Klebermass, E.-M.; Balber, T.; Pfaff, S.; Nics, L.; Mitterhauser, M.; Wadsak, W. An Overview of PET Radiochemistry, Part 1: The Covalent Labels18F,11C, and13N. J. Nucl. Med. 2018, 59, 1350-1354. [CrossRef]

3. Potter, M.; Newport, E.; Morten, K.J. The Warburg effect: 80 years on. Biochem. Soc. Trans. 2016, 44, 1499-1505. [CrossRef]

4. Flavell, R.R.; Naeger, D.M.; Aparici, C.M.; Hawkins, R.A.; Pampaloni, M.H.; Behr, S.C. Malignancies with Low Fluorodeoxyglucose Uptake at PET/CT: Pitfalls and Prognostic Importance:Resident and Fellow Education Feature. Radiographics 2016, 36, 293-294. [CrossRef] [PubMed]

5. Li, X.-F.; Du, Y.; Ma, Y.; Postel, G.C.; Civelek, A.C. 18F-Fluorodeoxyglucose Uptake and Tumor Hypoxia: Revisit 18FFluorodeoxyglucose in Oncology Application. Transl. Oncol. 2014, 7, 240-247. [CrossRef] [PubMed]

6. Hensley, C.T.; Faubert, B.; Yuan, Q.; Lev-Cohain, N.; Jin, E.; Kim, J.; Jiang, L.; Ko, B.; Skelton, R.; Loudat, L.; et al. Metabolic Heterogeneity in Human Lung Tumors. Cell 2016, 164, 681-694. [CrossRef] [PubMed]

7. Kernstine, K.H.; Faubert, B.; Do, Q.; Rogers, T.J.; Hensley, C.T.; Cai, L.; Torrealba, J.; Oliver, D.; Wachsmann, J.W.; Lenkinski, R.E.; et al. Does Tumor FDG-PET Avidity Represent Enhanced Glycolytic Metabolism in Non-Small Cell Lung Cancer? Ann. Thorac. Surg. 2020, 109, 1019-1025. [CrossRef] [PubMed]

8. Wienhard, K. Measurement of glucose consumption using [18F] fluorodeoxyglucose. Methods 2002, 27, 218-225. [CrossRef]

9. Izuishi, K.; Yamamoto, Y.; Mori, H.; Kameyama, R.; Fujihara, S.; Masaki, T.; Suzuki, Y. Molecular mechanisms of [18F]fluorodeoxyglucose accumulation in liver cancer. Oncol. Rep. 2013, 31, 701-706. [CrossRef]

10. Wiebe, L.I. FDG metabolism: Quaecumque sunt vera. J. Nucl. Med. 2001, 42, 1679-1681.

11. Southworth, R.; Parry, C.R.; Parkes, H.G.; Medina, R.A.; Garlick, P.B. Tissue-specific differences in 2-fluoro-2-deoxyglucose metabolism beyond FDG-6-P: a19F NMR spectroscopy study in the rat. NMR Biomed. 2003, 16, 494-502. [CrossRef] [PubMed]

12. Kanazawa, Y.; Yamane, H.; Shinohara, S.; Kuribayashi, S.; Momozono, Y.; Yamato, Y.; Kojima, M.; Masuda, K. 2-Deoxy-2-Fluoro-dGlucose as a Functional Probe for NMR: The Unique Metabolism Beyond Its 6-Phosphate. J. Neurochem. 2002, 66, 2113-2120. [CrossRef] [PubMed]

13. Kanazawa, Y.; Umayahara, K.; Shimmura, T.; Yamashita, T. 19F NMR of 2-Deoxy-2-fluoro-D-glucose for Tumor Diagnosis in Mice. An NDP-Bound Hexose Analog as a New NMR Target for Imaging. NMR Biomed. 1997, 10, 35-41. [CrossRef]

14. Suolinna, E.-M.; Haaparanta, M.; Paul, R.; Härkönen, P.; Solin, O.; Sipilä, H. Metabolism of 2-[18F]fluoro-2-deoxyglucose in tumor-bearing rats: Chromatographic and enzymatic studies. Int. J. Radiat. Appl. Instrument. Part B Nucl. Med. Biol. 1986, 13, 577-581. [CrossRef]

15. Kaarstad, K.; Bender, D.; Bentzen, L.; Munk, O.L.; Keiding, S. Metabolic fate of 18F-FDG in mice bearing either SCCVII squamous cell carcinoma or C3H mammary carcinoma. J. Nucl. Med. 2002, 43, 940-947. [PubMed]

16. Marini, C.; Ravera, S.; Buschiazzo, A.; Bianchi, G.; Orengo, A.M.; Bruno, S.; Bottoni, G.; Emionite, L.; Pastorino, F.; Monteverde, E.; et al. Discovery of a novel glucose metabolism in cancer: The role of endoplasmic reticulum beyond glycolysis and pentose phosphate shunt. Sci. Rep. 2016, 6, 25092. [CrossRef] [PubMed]

17. Sambuceti, G.; Cossu, V.; Bauckneht, M.; Morbelli, S.; Orengo, A.M.; Carta, S.; Ravera, S.; Bruno, S.; Marini, C. 18F-fluoro-2-deoxyd-glucose (FDG) uptake. What are we looking at? Eur. J. Nucl. Med. Mol. Imaging 2021, 48, 1278-1286. [CrossRef]

18. Rokka, J.; Grönroos, T.J.; Viljanen, T.; Solin, O.; Haaparanta-Solin, M. HPLC and TLC methods for analysis of [ 18 F]FDG and its metabolites from biological samples. J. Chromatogr. B 2017, 1048, 140-149. [CrossRef]

19. Meyer, G.-J.; Matzke, K.H.; Hamacher, K.; Füchtner, F.; Steinbach, J.; Notohamiprodjo, G.; Zijlstra, S. The stability of 2-[18F]fluorodeoxy-d-glucose towards epimerisation under alkaline conditions. Appl. Radiat. Isot. 1999, 51, 37-41. [CrossRef]

20. Horecker, B.L.; Smyrniotis, P.Z. Reversibility of glucose-6-phosphate oxidation. Biochim. Biophys. Acta Bioenerg. 1953, 12, 98-102. [CrossRef]

21. McSheehy, P.M.; Leach, M.O.; Judson, I.R.; Griffiths, J.R. Metabolites of 2'-fluoro-2'-deoxy-D-glucose detected by 19 F magnetic resonance spectroscopy in vivo predict response of murine RIF-1 tumors to 5-fluorouracil. Cancer Res. 2000, 60, $2122-2127$.

22. Shinohara, S.; Kanazawa, Y.; Kojima, M. Evaluation of energy metabolism in brain using epimerization of 2-deoxy-2-fluoro-dglucose by 19F NMR: The effect of anesthesia. Magn. Reson. Med. 1991, 21, 191-196. [CrossRef]

23. Keppler, D.; Keppler, A. Methods of Enzymatic Analysis, 3rd ed.; Verlag Chemie: Weinheim, Germany, $1984 ;$ p. 203.

24. Chou, J.Y.; Jun, H.S.; Mansfield, B.C. The SLC37 family of phosphate-linked sugar phosphate antiporters. Mol. Asp. Med. 2013, 34, 601-611. [CrossRef] [PubMed]

25. Cossu, V.; Marini, C.; Piccioli, P.; Rocchi, A.; Bruno, S.; Orengo, A.M.; Emionite, L.; Bauckneht, M.; Grillo, F.; Capitanio, S.; et al. Obligatory role of endoplasmic reticulum in brain FDG uptake. Eur. J. Nucl. Med. Mol. Imaging 2019, 46, 1184-1196. [CrossRef]

26. Markowetz, F.; Spang, R. Inferring cellular networks-A review. BMC Bioinform. 2007, 8, S5. [CrossRef] [PubMed]

27. Kulterer, O.C.; Niederstaetter, L.; Herz, C.T.; Haug, A.R.; Bileck, A.; Pils, D.; Kautzky-Willer, A.; Gerner, C.; Kiefer, F.W. The Presence of Active Brown Adipose Tissue Determines Cold-Induced Energy Expenditure and Oxylipin Profiles in Humans. J. Clin. Endocrinol. Metab. 2020, 105, 2203-2216. [CrossRef] [PubMed] 
28. Zois, C.E.; Harris, A.L. Glycogen metabolism has a key role in the cancer microenvironment and provides new targets for cancer therapy. J. Mol. Med. 2016, 94, 137-154. [CrossRef]

29. Spitz, D.R.; Sim, J.E.; Ridnour, L.A.; Galoforo, S.S.; Lee, Y.J. Glucose deprivation-induced oxidative stress in human tumor cells. A fundamental defect in metabolism? Ann. N. Y. Acad. Sci. 2006, 899, 349-362. [CrossRef] [PubMed]

30. Cherkas, A.; Holota, S.; Mdzinarashvili, T.; Gabbianelli, R.; Zarkovic, N. Glucose as a Major Antioxidant: When, what for and Why It Fails? Antioxidants 2020, 9, 140. [CrossRef]

31. Sprinz, C.; Altmayer, S.; Zanon, M.; Watte, G.; Irion, K.; Marchiori, E.; Hochhegger, B. Effects of blood glucose level on 18F-FDG uptake for PET/CT in normal organs: A systematic review. PLoS ONE 2018, 13, e0193140. [CrossRef]

32. Travaini, L.; Trifiro, G.; Paganelli, G. [18F] FDG uptake: Pay attention to candies. Ecancermedicalscience 2007, 1, 48. [CrossRef] [PubMed]

33. Rabkin, Z.; Israel, O.; Keidar, Z. Do Hyperglycemia and Diabetes Affect the Incidence of False-Negative 18F-FDG PET/CT Studies in Patients Evaluated for Infection or Inflammation and Cancer? A Comparative Analysis. J. Nucl. Med. 2010, 51, 1015-1020. [CrossRef]

34. Jahromi, A.H.; Fallahzadeh, M.K.; Takalkar, A.; Sheng, J.; Zibari, G.; Amiri, H.S. Impact of Plasma Glucose Level at the Time of Fluorodeoxyglucose Administration on the Accuracy of FDG-PET/CT in the Diagnosis of Pancreatic Lesions. Int. J. Endocrinol. Metab. 2014, 12, e16429. [CrossRef]

35. Boellaard, R.; Delgado-Bolton, R.; Oyen, W.J.G.; Giammarile, F.; Tatsch, K.; Eschner, W.; Verzijlbergen, F.J.; Barrington, S.F.; Pike, L.C.; Weber, W.A.; et al. FDG PET/CT: EANM procedure guidelines for tumour imaging: Version 2.0. Eur. J. Nucl. Med. Mol. Imaging 2015, 42, 328-354. [CrossRef] [PubMed]

36. Sullivan, M.R.; Heiden, M.G.V. Determinants of nutrient limitation in cancer. Crit. Rev. Biochem. Mol. Biol. 2019, 54, 193-207. [CrossRef] [PubMed]

37. Lindl, T.; Gstraunthaler, G. Zell- und Gewebekultur, 6th ed.; Spektrum Akademischer Verlag: Heidelberg, Germany, 2008 ; p. 95.

38. González, O.; Alonso, R.M. Chapter 6-Validation of bioanalytical chromatographic methods for the quantification of drugs in biological fluids. In Handbook of Analytical Separations; Hempel, G., Ed.; Elsevier Science B.V.: Amsterdam, The Netherlands, 2020; Volume 7, pp. 115-134.

39. Perisic, O. Heterodimer Binding Scaffolds Recognition via the Analysis of Kinetically Hot Residues. Pharmaceuticals 2018, 11, 29. [CrossRef] [PubMed] 